\title{
MRS/MRS-Mexico Hold Inaugural Joint Meeting
}

"Mark your calendars: XVIII International Materials Research Congress in Cancun, Mexico, August 16-20, 2009-an MRS/ MRS-Mexico Joint Summer Meeting!"

The core mission of the Materials Research Society is to make knowledge gained through materials research as widely available as possible. Because knowledge gained anywhere can benefit people everywhere, MRS has always worked to promote leading-edge research from around the world. Materials research is a truly global enterprise.

In that spirit, I am proud to be able to announce that the Materials Research Society (MRS) and the Sociedad Mexicana de Materiales (MRS-Mexico) are working together to grow the International Materials Research Congress (IMRC) held annually in Cancun, Mexico.

The IMRC offers a range of symposium topics of interest to MRS members and has become a popular destination in recent years with about 1500 attendees from around the world. This year, six symposia organized jointly by MRS and MRS-Mexico will complement 17 IMRC symposia.

The MRS/MRS-Mexico joint symposia were developed using the same process that has made the MRS Fall and Spring Meetings so successful, namely, by choosing symposia based on proposals sub-

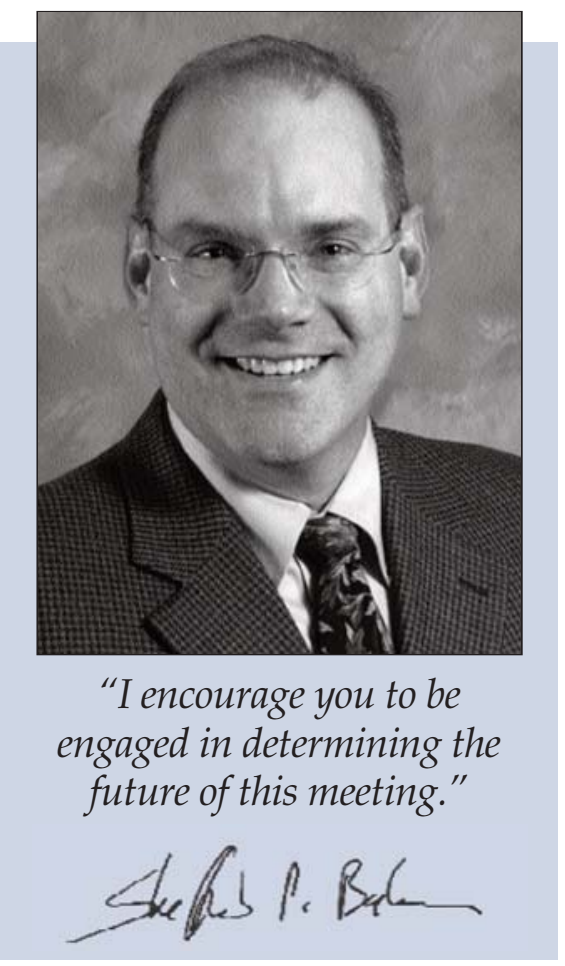

mitted from the broad, international materials community. This year, Meeting Chairs Luis Enrique Sansores Cuevas (Materials Research institute/Universidad
Nacional Autónoma de México, Mexico) and Alan J. Hurd (Los Alamos National Laboratory, USA) have constructed an exciting program based on symposium proposals submitted by materials researchers from the United States, Latin America, Europe, and Asia.

MRS and MRS-Mexico intend to work collaboratively to grow this meeting in the future. This annual event will provide additional high-level meeting capacity in a readily accessible and attractive location. As has always been true of the MRS Fall and Spring Meetings, a "bottom up" approach will allow this "Summer Meeting" to evolve rapidly in real time to meet the needs of the materials research community.

I encourage you to be engaged in determining the future of this meeting. Please look at the program for the 2009 IMRC meeting online at www.mrs.org/mex09 to see if this might be a good venue for you to present your latest and greatest research results. Furthermore, if you have a materials research topic that you think might be appropriate for this new venue in 2010 or 2011, please submit your proposal online at www.mrs.org/mex09.

I hope to see you in Mexico!

SHEFFORD P. BAKER 2009 MRS President

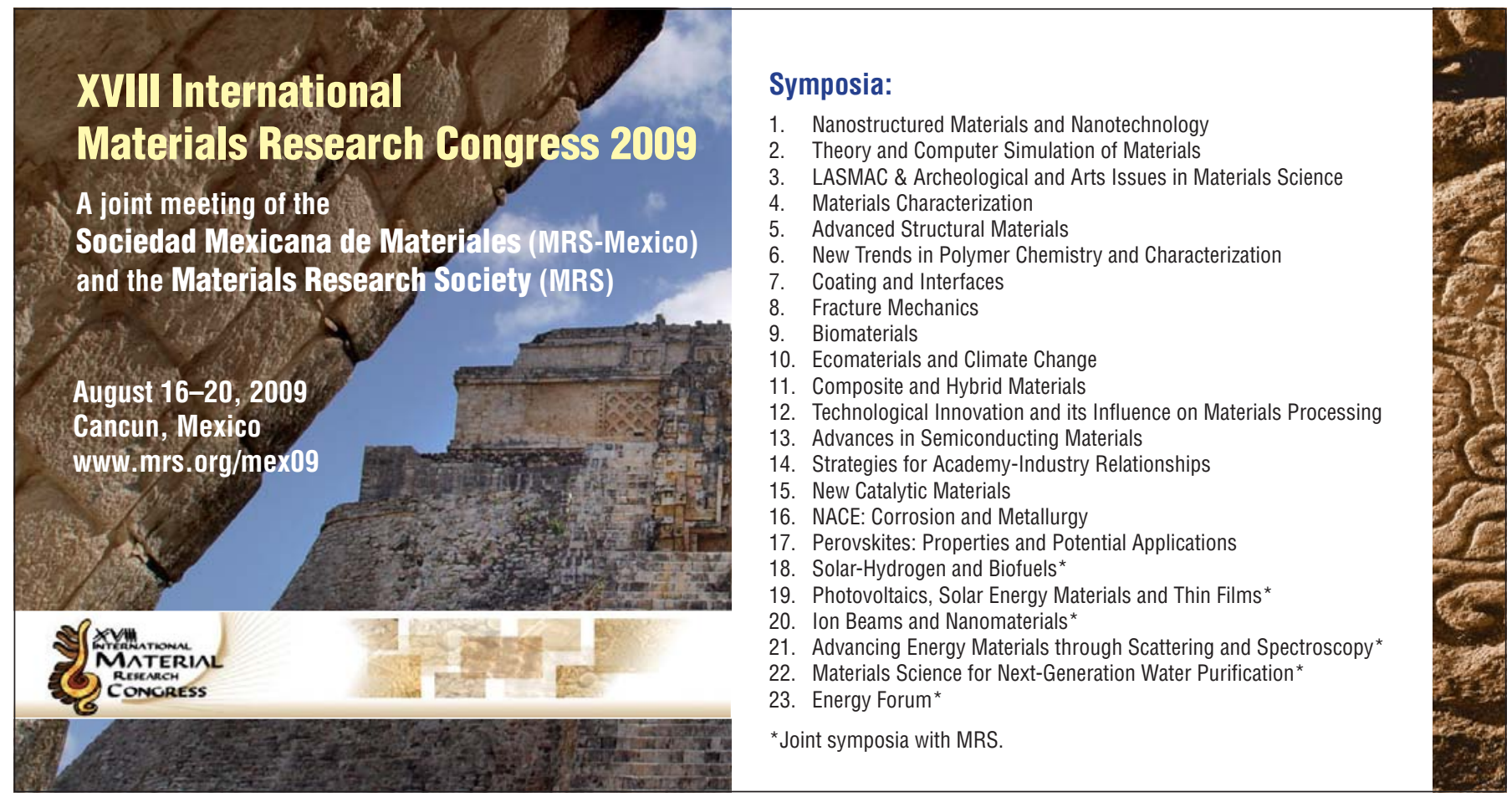

